\title{
Limiting Reinforcement Ratios for Hybrid GFRP/Steel Reinforced Concrete Beams
}

\author{
Duy Phan Nguyen ${ }^{1, *}$, Viet Quoc Dang ${ }^{2}$ \\ ${ }^{1}$ Faculty of Civil Engineering; ${ }^{2}$ Faculty of bridge and road construction, Mientrung University of Civil Engineering, \\ Phuyen, Vietnam \\ Received 30 October 2020; received in revised form 25 December 2020; accepted 05 January 2021 \\ DOI: https://doi.org/10.46604/ijeti.2021.6660
}

\begin{abstract}
In this work, a theoretical approach is proposed for estimating the minimum and maximum reinforcement ratios for hybrid glass fiber reinforced polymer (GFRP)/steel-reinforced concrete beams to prevent sudden and brittle failure as well as the compression failure of concrete before the tension failure of reinforcements. Equilibrium equations were used to develop a method for determining the minimum hybrid GFRP/steel reinforcement ratio. A method for determining the maximum hybrid GFRP/steel reinforcement ratio was also developed based on the equilibrium of forces of the balanced failure mode. For estimating the load-carrying capacity of concrete beams reinforced with hybrid GFRP/steel, less than the minimum and more than the maximum reinforcement ratio is recommended. Comparisons between the proposed expressions, experimental data, and available test results in the literature shows good agreement between the theoretical and experimental data, with a maximum discrepancy of $7 \%$.
\end{abstract}

Keywords: GFRP, hybrid reinforcement, reinforcement ratio

\section{Introduction}

Since the 1980s, fiber reinforced polymer (FRP) reinforcement has been used in modern construction [1-3] to replace conventional steel bars in reinforced concrete $(\mathrm{RC})$ structures in specific environments [2-4]. Glass fiber reinforced polymer (GFRP) is one of the FRPs with high tensile strength and low elastic modulus. Thus, a concrete beam reinforced with GFRP exhibits a higher deflection and wider crack width than that reinforced with steel bars [5-8]. Many researchers have suggested adding longitudinal steel bars to GFRP RC beams to improve their flexural performance; hence, hybrid FRP/steel RC beams were developed. Experimental studies have shown that the ductility of hybrid GFRP/steel RC beams is significantly enhanced compared with that of pure GFRP RC beams. Moreover, steel reinforcement increases the flexural stiffness of GFRP RC beams, and hybrid GFRP RC beams exhibit lower deflection, smaller crack width, and higher load-carrying capacity compared with the concrete beams reinforced with GFRP bars [9-15]. Depending on the hybrid reinforcement ratios, six failure modes, including two balanced failure modes, have been identified for hybrid GFRP/steel RC beams [15]. Based on the classification of failure modes, researchers have proposed formulas to determine the load-carrying capacity of hybrid GFRP/steel RC beams [12, 14-16]. According to many researchers, for hybrid GFRP/steel RC beams, the preferred failure mode is concrete crushing after the yielding of steel [15-18]. To the best of our knowledge, previous studies have focused on the classification of the failure modes of hybrid GFRP/steel RC beams, and proposed analytical equations to separate these failure modes according to their reinforcement ratios. There are no studies on limits on the minimum and maximum reinforcement ratios of concrete beams reinforced with hybrid GFRP/steel bars.

* Corresponding author. E-mail address: nguyenphanduy@ muce.edu.vn Tel.: +84-917688903 
For conventional RC, the minimum and maximum reinforcement ratios are set by various design standards. According to SP 63.13330.2018 [19], the minimum reinforcement ratio for RC beams $\left(\mu_{s, m i n}\right)$ should be greater than $0.1 \%$ to ensure that the beam can still carry a load after the appearance of the first crack. This standard also limits the maximum reinforcement ratio for steel RC beams $\left(\mu_{s, \max }\right)$ to prevent concrete crushing in the compression zone as follows:

$$
\mu_{s, \max }=\frac{R_{b}}{R_{s}} \xi_{R}, \%
$$

where $\xi_{R}$ is the relative height limit of the compression zone.

ACI 318-19 [20] sets the minimum area of steel reinforcement in beams as follows:

$$
A_{s, \min }=\max \left(\frac{\sqrt{f_{c}^{\prime}}}{4 f_{y}} b_{w} d ; \frac{1.4}{f_{y}} b_{w} d\right)
$$

where $f_{c}$ ' is the compressive strength of concrete, $f_{y}$ is the yield strength of the steel bar, $b_{w}$ is the width of a rectangular section or T-section, and $d$ is the effective depth of the beam.

According to ACI 318-19 [20-21], the maximum reinforcement ratio for steel RC concrete beams is determined as follows:

$$
\rho_{\max }=\frac{0.85 \beta_{1} f_{c}^{\prime}}{f_{y}}\left(\frac{E_{s} \varepsilon_{c u}}{E_{s} \varepsilon_{c u}+f_{y}}\right)
$$

where $\beta_{1}=0.85, E_{s}$ is the elastic modulus of the steel bar, and $\varepsilon_{c u}$ is the ultimate compressive strain in concrete.

For a FRP RC concrete beam, SP 295.1325800.2017 [22] sets the minimum FRP reinforcement ratio as

$$
\mu_{f, \min }=\max \left(26 \frac{R_{b t}}{R_{f}} ; 0.13 \%\right)
$$

Similarly, ACI 440.1R-15 [23] recommends the minimum area of FRP reinforcement as

$$
A_{f, \min }=\max \left(\frac{0.41 \sqrt{f_{c}^{\prime}}}{f_{f u}} b_{w} d ; \frac{2.3 b_{w} d}{f_{f u}}\right)
$$

where $f_{f u}$ is the tensile strength of the FRP bar.

FRP reinforcement bars have a higher tensile strength and lower elastic modulus than steel bars. Therefore, to hinder the development of crack widths and deflections, FRP RC beams are often designed as over-reinforced, and many design standards do set limits on the maximum FRP reinforcement ratio.

There are some approaches to develop formulas for determining the limiting reinforcement ratios for RC beams. The most popular methods are the fracture mechanics method and equilibrium equations method, which equate the cracking moment $M_{c r}$ to the flexural strength $M_{u}$ [24-25]. The latter method is used in existing standards and design codes.

In this work, a theoretical approach based on the equilibrium equations method for the minimum and maximum hybrid GFRP/steel reinforcement ratios in beams subjected to flexure, associated with minimum and maximum strength at ultimate limit state, is presented. The analytical formulas for determining the load-carrying capacity of hybrid GFRP/steel RC beams with reinforcement lower than the minimum reinforcement ratio and higher than the maximum reinforcement ratio, are introduced. Comparisons were made between the proposed expressions and test results. 


\section{Minimum Reinforcement Ratio for Hybrid GFRP/Steel RC Beam}

\subsection{Cracking moment of a plain concrete beam}

SP 63.13330.2018 [19] introduced a simple formula to determine the cracking moment of a plain concrete beam, under the assumption that the concrete in the tension and compression zones behaves elastically. Accordingly, the cracking moment of a plain concrete beam with a rectangular cross-section $b \times h$ is equal to the section modulus $W$ time tensile strength of concrete $R_{b t}(6)$. In fact, prior to concrete cracking, the concrete in the tension zone behaves inelastically. Therefore, the theoretical cracking moment according to Eq. (6) is smaller than the actual cracking moment.

$$
M_{c r c, b}=R_{b t} W=R_{b t} \frac{b h^{2}}{6}
$$

To accurately estimate the cracking moment of concrete beams, it is necessary to consider the nonlinear behavior of concrete in the tension zone. This section introduces an analytical method for calculating the cracking moment of a plain concrete beam, which considers the inelastic behavior of concrete in the tension zone. To determine the cracking moment, the bilinear simplified stress-strain relationship of concrete introduced in SP 63.13330.2018 [19] was used, as shown in Fig. 1. In a plain concrete beam, the first normal crack occurs when the tensile strain and stress at the outermost tension face reach their ultimate values, that is, $\varepsilon_{b t}=\varepsilon_{b t u}=\varepsilon_{b t 2}$ and $\sigma_{b t}=R_{b t}$ (Fig. 1). The stress-strain distribution at the normal cross-section just before concrete cracking is shown in Fig. 2. Before cracking, assuming that the concrete in compression behaves elastically, a triangular stress profile can be adopted. For concrete in tension, considering the plastic behavior of concrete, the trapezoidal shape of the stress block with a peak tensile strength of $R_{b t}$ according to the stress-strain curve of concrete (Fig. 1) was used [19].

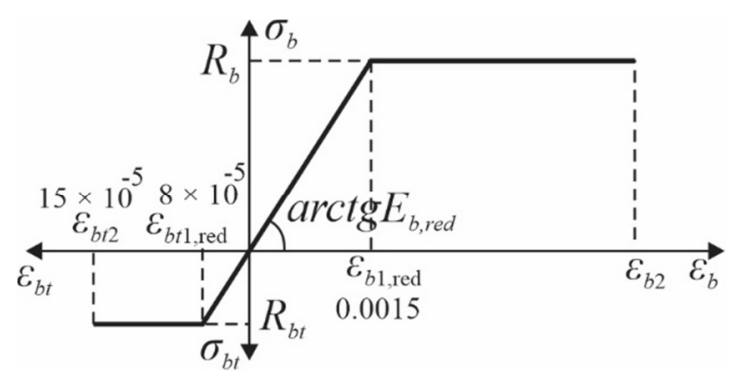

Fig. 1 Bilinear stress-strain curve of concrete [19]

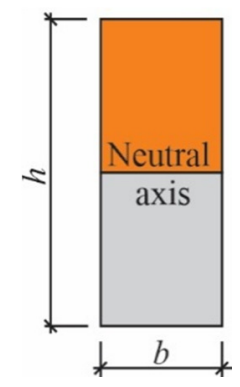

(a) Cross-section

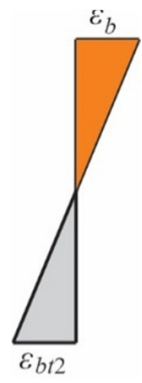

(b) Strain distribution

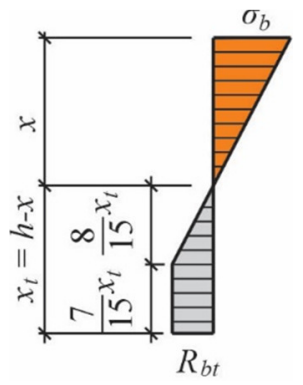

(c) Stress distribution

Fig. 2 Distribution of strain and stress at the normal cross-section at the moment before cracking for a plain concrete beam

Based on the stress distribution at the normal cross-section in Fig. 2(c), the cracking moment is determined by taking the moment about the axis passing through the neutral surface as follows:

$$
M_{c r c, b}=\frac{\sigma_{b} b x^{2}}{3}+\frac{611 R_{b t} b(h-x)^{2}}{1350}
$$


where $x$ is the height of the compression zone, which was calculated by considering the equilibrium of the cross-section, $\sigma_{b}$ is the compressive stress in concrete at the outermost face before concrete tension zone cracking, which can be determined as follows:

$$
\sigma_{b}=\varepsilon_{b} E_{b, r e d}=\frac{\varepsilon_{b t u} x}{h-x} E_{b, r e d}=\frac{\varepsilon_{b t u} x}{h-x} \frac{R_{b}}{\varepsilon_{b 1 r e d}}=\frac{x}{h-x} \frac{R_{b}}{10}
$$

where $E_{b, \text { red }}=R_{b} / \varepsilon_{b 1 \text { red }}, R_{b}$ is the prism compressive strength of concrete, and $\varepsilon_{b 1 \text { red }}=0.0015$ and $\varepsilon_{b t u}=\varepsilon_{b t 2}=0.00015$ (Fig. 1) [19].

The equilibrium of forces according to Fig. 2(c) is

$$
\frac{x^{2}}{h-x} \frac{b R_{b}}{20}=\frac{11 R_{b t} b(h-x)}{15}
$$

By setting $r=R_{b} / R_{b t}$ and $\xi=x / h$ as the relative compression height, substituting these variables into Eq. (9), and then solving this equation, the relative height of the compression zone is obtained as follows:

$$
\xi=\frac{11.49 \sqrt{r}-44}{3 r-44}
$$

Substituting Eq. (8) into Eq. (7), the formula for determining the cracking moment of a plain concrete beam is

$$
M_{c r c, b}=R_{b t} b h^{2}\left[\frac{r \xi^{3}}{30(1-\xi)}+\frac{611(1-\xi)^{2}}{1350}\right]
$$

\subsection{Load-carrying capacity of a hybrid GFRP/steel under RC beam}

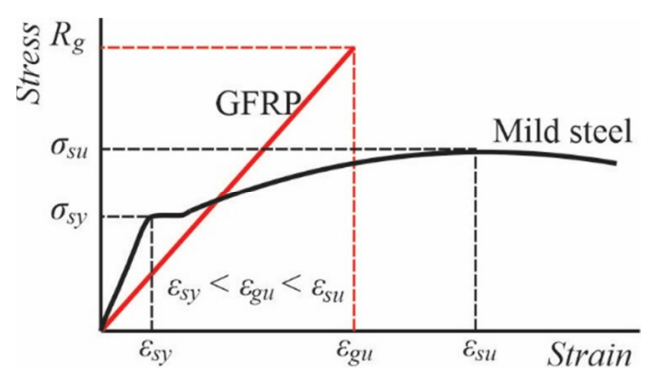

Fig. 3 Schematic stress-strain diagrams of steel and GFRP [26-27]

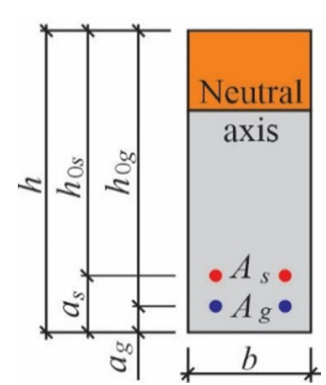

(a) Cross-section

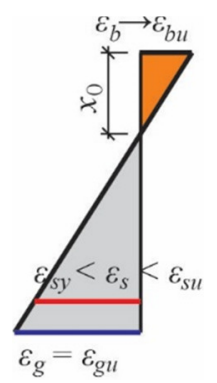

(b) Strain distribution

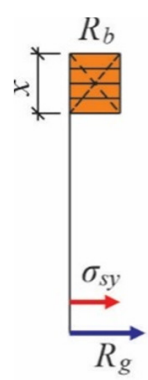

(c) Stress distribution

Fig. 4 Distribution of strain and equivalent stress at the normal cross-section upon failure for an under-reinforced hybrid GFRP/steel RC beam

In a hybrid GFRP/steel under RC beam, the failure of the normal cross-section occurs in the following sequence: first, the steel bars yield; then, the GFRP bars rupture, which crushes the concrete in the compression zone [15]. It should be noted that the rupture strain of FRP bar $\varepsilon_{f u}$ is higher than the yield strain of steel bar $\varepsilon_{s y}$, and is much lower than the ultimate strain of the 
steel bar (Fig. 3). Therefore, upon the rupture of the FRP bar, the steel bar still works in the yield stage= The distribution of strain and equivalent stress at the normal cross-section of the beam is shown in Fig. 4.

The height of the concrete compression zone $x$ can be obtained from the equilibrium of the internal forces:

$$
x=\frac{R_{g} A_{g}+\sigma_{s y} A_{s}}{R_{b} b}
$$

where $R_{g}$ and $A_{g}$ are the tensile strength and total area of GFRP bars; and $\sigma_{s y}$ and $A_{s}$ are the yield strength and total area of steel bars, respectively.

The moment capacity of the normal cross-section $M_{u}$ can be determined by taking the moment about the axis passing through the centroid of the equivalent concrete compressive stress block as follows:

$$
M_{u}=R_{g} A_{g}\left(h_{0 g}-\frac{R_{g} A_{g}+\sigma_{s y} A_{s}}{2 R_{b} b}\right)+\sigma_{s y} A_{s}\left(h_{0 s}-\frac{R_{g} A_{g}+\sigma_{s y} A_{s}}{2 R_{b} b}\right)
$$

where $h_{0 g}$ and $h_{0 s}$ are the distances from the outermost compression face to the centroids of the GFRP and steel bars, respectively (Fig. 4).

\subsection{Minimum hybrid GFRP/steel reinforcement ratio}

If the failure of a hybrid GFRP/steel RC beam is controlled by the yielding of steel and rupturing of FRP, then a minimum amount of hybrid GFRP/steel reinforcement should be provided to prevent failure upon concrete cracking [24-28]:

$$
\phi M_{u}=M_{c r c, b}
$$

where $\phi$ is the strength reduction factor of the beam, $\phi \leq 1$.

The following equation can be expressed by the combination of Eqs. (11), (13), and (14):

$$
\phi\left[R_{g} A_{g}\left(h_{0 g}-\frac{R_{g} A_{g}+\sigma_{s y} A_{s}}{2 R_{b} b}\right)+\sigma_{s y} A_{s}\left(h_{0 s}-\frac{R_{g} A_{g}+\sigma_{s y} A_{s}}{2 R_{b} b}\right)\right]=R_{b t} b h^{2}\left[\frac{r \xi^{3}}{30(1-\xi)}+\frac{611(1-\xi)^{2}}{1350}\right]
$$

Setting $\mu_{g}=A_{g} /\left(b h_{0 g}\right)$ as the GFRP reinforcement ratio, $\mu_{s}=A_{s} /\left(b h_{0 s}\right)$ as the steel reinforcement ratio, and $\alpha_{s}=\sigma_{s y} / R_{b}, \alpha_{g}=R_{g} / R_{b}$, then Eq. (15) can be simplified as follows:

$$
\begin{aligned}
& \phi\left[\alpha_{g} R_{b} b \mu_{g} h_{0 g}^{2}\left(1-\frac{\mu_{g} \alpha_{g}}{2}-\frac{\mu_{s} \alpha_{s} h_{0 s}}{2 h_{0 g}}\right)+\alpha_{s} R_{b} b \mu_{s} h_{0 s}^{2}\left(1-\frac{\mu_{g} \alpha_{g} h_{0 g}}{2 h_{0 s}}-\frac{\mu_{s} \alpha_{s}}{2}\right)\right] \\
= & R_{b t} b h^{2}\left[\frac{r \xi^{3}}{30(1-\xi)}+\frac{611(1-\xi)^{2}}{1350}\right]
\end{aligned}
$$

Assuming that $h_{0 g}=h_{0 s}$ and $r=R_{b} / R_{b t}$, we simplify Eq. (16) and obtain the following equation:

$$
\frac{\phi h_{0 s}^{2}\left(\mu_{g} \alpha_{g}+\mu_{s} \alpha_{s}\right)\left(2-\mu_{g} \alpha_{g}-\mu_{s} \alpha_{s}\right)}{2}=\frac{h^{2}}{r}\left[\frac{r \xi^{3}}{30(1-\xi)}+\frac{611(1-\xi)^{2}}{1350}\right]
$$

The following hybrid reinforcement ratio can be set:

$$
\mu_{s g}=\alpha_{s} \mu_{s}+\alpha_{g} \mu_{g}
$$

Combining Eqs. (17) and (18): 


$$
\frac{\phi h_{0 s}^{2} \mu_{s g}\left(2-\mu_{s g}\right)}{2}=\frac{h^{2}}{r}\left[\frac{r \xi^{3}}{30(1-\xi)}+\frac{611(1-\xi)^{2}}{1350}\right]
$$

The minimum hybrid GFRP/steel reinforcement ratio for the concrete beam can be obtained by solving Eq. (19) as follows:

$$
\mu_{s g, \min }=1-\sqrt{1-\frac{2 h^{2}}{\phi r h_{0 s}^{2}}\left[\frac{r \xi^{3}}{30(1-\xi)}+\frac{611(1-\xi)^{2}}{1350}\right]}
$$

The load-carrying capacity of concrete reinforced with a hybrid GFRP/steel reinforcement ratio $\mu_{s g}$ below the minimum requirement $\mu_{s g, m i n}$ is recommended to obtain the equal cracking moment of the corresponding plain concrete beam, that is, by Eq. (11).

\section{Maximum Hybrid GFRP/Steel Reinforcement Ratio}

The hybrid GFRP/steel reinforcement ratio for a concrete beam should be limited so that concrete crushing in the compression zone does not occur until the yielding of steel. To determine the maximum hybrid GFRP/steel reinforcement ratio, the balanced failure mode, in which the yielding of steel and concrete crushing occur simultaneously, is used. In this case, the strain and stress in concrete at the outermost face reach their ultimate values, that is, $\varepsilon_{b}=\varepsilon_{b u}=3.5 \times 10^{-3}$ and $\sigma_{b}=R_{b}$. The strain and stress in the steel bars also reached $\varepsilon_{s}=\varepsilon_{s y}=\sigma_{s y} / E_{s}$ and $\sigma_{s}=\sigma_{s y}$ at the yield point. However, the tensile strain and stress in GFRP bars have not reached their ultimate values. The distribution of strain and stress at the normal cross-section of the beam is shown in Fig. 5.

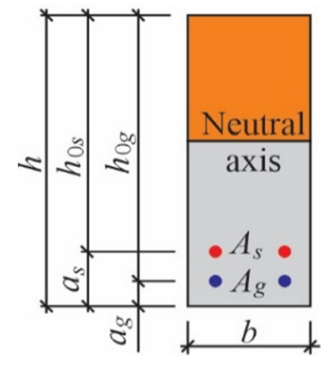

(a) Cross-section

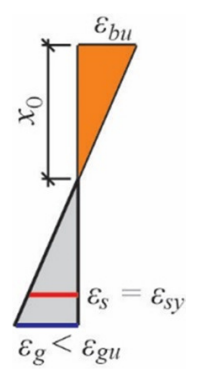

(b) Strain distribution

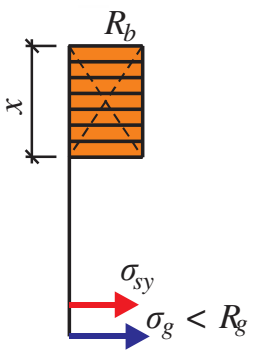

(c) Stress distribution

Fig. 5 Distribution of strain and stress at the normal cross-section for balanced failure mode of the hybrid GFRP/steel RC beam

From Fig. 5(b), the height of the concrete compression zone $x_{0}$ is determined according to the strain compatibility as follows:

$$
x=x_{0} \omega=\omega h_{0 s} \frac{\varepsilon_{b u}}{\varepsilon_{s y}+\varepsilon_{b u}}
$$

where $x$ is the height of the equivalent rectangular concrete compressive stress block, $x_{0}$ is the neutral axis depth, and $\omega=x / x_{0}$ $=0.85[23]$.

The force equilibrium condition is as follows:

$$
R_{b} b x=R_{b} b \omega x_{0}=\sigma_{s y} A_{s}+\sigma_{g} A_{g}
$$

where $\sigma_{g}$ is the stress in the GFRP bars, which is determined by considering the linear behavior of the GFRP bar until failure and the strain compatibility (Fig. 5):

$$
\sigma_{g}=\varepsilon_{g} E_{g}=\frac{\varepsilon_{s y} E_{g}\left(h_{0 g}-x_{0}\right)}{h_{0 s}-x_{0}}
$$


Substituting Eqs. (21) and (23) into Eq. (22), and setting $\alpha=h_{0 s} / h_{0 g}$, the force equilibrium condition can be rewritten as

$$
\mu_{s}+\mu_{g} \frac{E_{g}}{E_{s}} \frac{\left(\varepsilon_{b u}+\varepsilon_{s y}-\alpha \varepsilon_{b u}\right)}{\alpha^{2} \varepsilon_{s y}}=\frac{R_{b} \omega \varepsilon_{b u}}{\sigma_{s y}\left(\varepsilon_{b u}+\varepsilon_{s y}\right)}
$$

Denoting the left side of Eq. (24) as the nominal hybrid reinforcement ratio converted by the elastic modulus $\mu_{\text {nom,E }}$, and the right side as the maximum hybrid GFRP/steel reinforcement ratio $\mu_{s g, \text { max }}$, the following equations can be expressed:

$$
\begin{aligned}
& \mu_{s g, E}=\mu_{s}+\mu_{g} \frac{E_{g}}{E_{s}} \frac{\left(\varepsilon_{b u}+\varepsilon_{s y}-\alpha \varepsilon_{b u}\right)}{\alpha^{2} \varepsilon_{s y}} \\
& \mu_{s g, \max }=\frac{R_{b} \omega \varepsilon_{b u}}{\sigma_{s y}\left(\varepsilon_{b u}+\varepsilon_{s y}\right)}
\end{aligned}
$$

The hybrid GFRP/steel reinforcement ratio for the concrete beam should therefore be regulated so that concrete crushing in the compression zone does not occur until the yielding of steel:

$$
\mu_{s g, E}=\mu_{s}+\mu_{g} \frac{E_{g}}{E_{s}} \frac{\left(\varepsilon_{b u}+\varepsilon_{s y}-\alpha \varepsilon_{b u}\right)}{\alpha^{2} \varepsilon_{s y}} \leq \mu_{s g, \max }=\frac{R_{b} \omega \varepsilon_{b u}}{\sigma_{s y}\left(\varepsilon_{b u}+\varepsilon_{s y}\right)}
$$

The moment capacity of the beam can be obtained by taking the moment about the axis passing through the centroid of the tensile GFRP bars (Fig. 5):

$$
M_{u}=\frac{R_{b} b \omega h_{0 s} \varepsilon_{b u}\left(h_{0 g}-\frac{1}{2} \frac{\omega h_{0 s} \varepsilon_{b u}}{\varepsilon_{b u}+\varepsilon_{s y}}\right)}{\varepsilon_{b u}+\varepsilon_{s y}}-A_{s} \sigma_{s y}\left(h_{0 g}-h_{0 s}\right)
$$

From Eq. (27), the maximum reinforcement ratio for the hybrid concrete beam depends on the compressive strength of concrete, the yield strength of steel bars, the ultimate compressive strain in concrete, and the tensile strain of the steel bars at the yield point.

\section{Validation of Theoretical Equations through the Experiment Results}

To verify the proposed analytical equations for determining the minimum and maximum hybrid GFRP/steel reinforcement ratios, two hybrid GFRP/steel RC beams with dimensions of $150 \mathrm{~mm} \times 250 \mathrm{~mm} \times 2700 \mathrm{~mm}(b \times h \times l) \mathrm{were}$ fabricated and tested. The beam specimens were tested in a four-point bending machine, with a testing span $\left(l_{0}\right)$ of $2400 \mathrm{~mm}$, of which the pure bending length was $400 \mathrm{~mm}$. The hybrid GFRP/steel reinforcement in the first beam (denoted as B1) was regulated according to Eqs. (18) and (20) such that $\mu_{s g}<\mu_{s g, \min }$. The second beam (denoted as B2) was designed in line with the conditions of $\mu_{s g, E}>\mu_{s g, \max }$ according to Eq. (27). In the hybrid GFRP/steel RC beams, the GFRP and steel bars were arranged in two layers. The GFRP bars were located closer to the surface with a cover thickness $\left(C_{g}\right)$ of $20 \mathrm{~mm}$, while the steel rebars were located deeper with a cover thickness $\left(C_{s}\right)$ of $50 \mathrm{~mm}$. For beam B1, one GFRP bar with a diameter of $5 \mathrm{~mm}$ and a plain round steel bar with a diameter of $6 \mathrm{~mm}$ were used as tensile reinforcements; one plain round steel bar with a diameter of $6 \mathrm{~mm}$ was used as the compressive reinforcement. Single-legged stirrups from plain round steel bars with a diameter of $6 \mathrm{~mm}$ and spacings of $100 \mathrm{~mm}$ and $200 \mathrm{~mm}$ in shear span and midspan, respectively, were used. For beam B2, three GFRP bars with a diameter of $20 \mathrm{~mm}$ and three ribbed steel bars with a diameter of $20 \mathrm{~mm}$ were used as tensile reinforcements, and two plain round steel bars with diameter of $6 \mathrm{~mm}$ were used as compressive reinforcements. Double-legged stirrups from plain round steel bars with a diameter of $6 \mathrm{~mm}$ and spacings of $100 \mathrm{~mm}$ and $200 \mathrm{~mm}$ in shear span and midspan, respectively, were used. Details of the testing beams and the experimental scheme are shown in Fig. 6. 


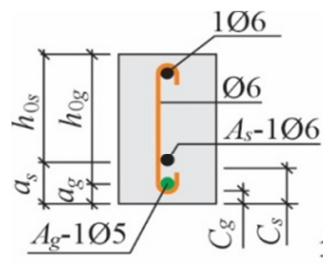

Beam B1

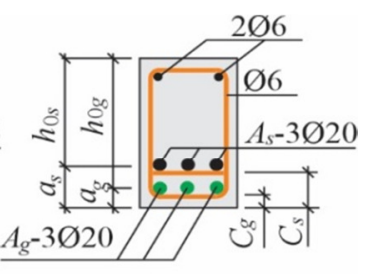

Beam B2

(a) Cross-sections of testing beams

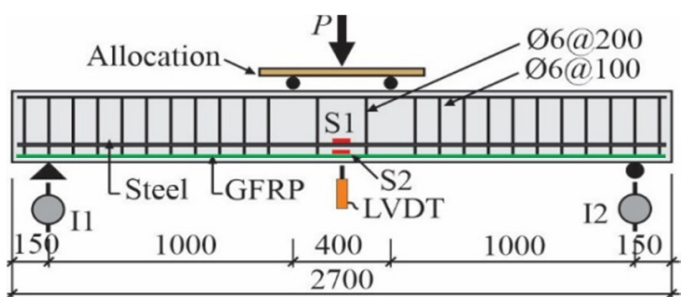

(b) Beam design and loading scheme

Fig. 6 Details of the experimental hybrid GFRP/steel RC beams (mm)

The concrete mixture proportion was designed to achieve the expected compressive strength of 40 MPa in 28 days. Ordinary Portland cement, coarse aggregates with a maximum size of $20 \mathrm{~mm}$, and river sand were used in this study. The details on the proportions of the concrete mixture are listed in Table 1 . According to the tensile test, the actual yield $\sigma_{s y}$ and tensile strengths $\sigma_{s u}$ of the ribbed steel bars were $410 \mathrm{MPa}$ and $570 \mathrm{MPa}$, respectively. The corresponding values for the plain round steel bar are $309 \mathrm{MPa}$ and $410 \mathrm{MPa}$, respectively. The tensile strength $R_{g}$ and elastic modulus $E_{g}$ of the GFRP bar provided by the manufacturer were $970 \mathrm{MPa}$ and $44300 \mathrm{MPa}$, respectively. The average cubic compressive strength $R_{m}$ of each concrete beam was evaluated by testing five cubic specimens $(150 \mathrm{~mm} \times 150 \mathrm{~mm} \times 150 \mathrm{~mm})$ after 28 days of curing. The material properties and detailed dimensions of the beams are listed in Table 2.

Table 1 Mixture proportion of concrete (for $1 \mathrm{~m}^{3}$ )

\begin{tabular}{|c|c|c|c|}
\hline OPC, $\mathrm{kg}$ & Gravel, $\mathrm{kg}$ & Sand, $\mathrm{kg}$ & Water, lit \\
\hline 350 & 1130 & 650 & 195 \\
\hline
\end{tabular}

To verify the applicability of the proposed formula (13) for determining the load-carrying capacity of hybrid GFRP/steel under RC beams, the experimental data from tested beams in the literature were collected, as shown in Tables 2 and 3.

Table 2 The properties of the experimental beam

\begin{tabular}{|c|c|c|c|c|c|c|c|c|c|c|c|c|c|c|c|c|c|c|c|c|}
\hline Ref & $\begin{array}{c}\text { Beam } \\
\text { ID }\end{array}$ & $\begin{array}{c}b \times h, \\
m m\end{array}$ & $\begin{array}{c}C_{g}, \\
m m\end{array}$ & $\begin{array}{c}C_{s}, \\
m m\end{array}$ & $\begin{array}{l}h_{0 g} \\
m m\end{array}$ & $\begin{array}{l}h_{0 s} \\
m m\end{array}$ & $\begin{array}{c}\text { Reinfor- } \\
\text { cement }\end{array}$ & $\begin{array}{l}A_{g} \\
\mathrm{~cm}^{2}\end{array}$ & \begin{tabular}{|l|}
$A_{s}$, \\
$\mathrm{cm}^{2}$
\end{tabular} & $\begin{array}{l}\mu_{g}, \\
\%\end{array}$ & $\begin{array}{l}\mu_{s}, \\
\%\end{array}$ & $\begin{array}{l}R_{m} \\
M P a\end{array}$ & $\begin{array}{c}R_{b} \\
M P a\end{array}$ & $\begin{array}{l}R_{b b} \\
M P a\end{array}$ & \begin{tabular}{|l|}
$E_{b}$ \\
$G P a$
\end{tabular} & \begin{tabular}{|l|}
$\sigma_{s y}$, \\
$M P a$
\end{tabular} & $\begin{array}{c}\sigma_{s u} \\
M P a\end{array}$ & \begin{tabular}{|c|}
$E_{S,}$ \\
$G P a$
\end{tabular} & \begin{tabular}{|c|}
$R_{g}$ \\
$M P a$ \\
\end{tabular} & \begin{tabular}{|c|}
$E_{g}$ \\
$G P a$ \\
\end{tabular} \\
\hline \multirow{2}{*}{ This study } & $\mathrm{B} 1$ & $50 \times 250$ & 20 & 50 & 227 & 197 & & 0.13 & 0.28 & 0.038 & 0.096 & 38.1 & 30.5 & 2.3 & 32.1 & 309 & 358 & 200 & 970 & 44.3 \\
\hline & & & 2 & 60 & 220 & 180 & 20 & 7.79 & 9.42 & 2.36 & 9 & .7 & 2 & .4 & 3.7 & 10 & 70 & 200 & 70 & 4.3 \\
\hline $\mathrm{L}$ & A ע & $280 \times 380$ & - & - & 351 & 51 & - & 284 & 98 & 0.3 & 1.03 & 48 & 8.4 & 2.58 & 35.2 & 336 & 470 & 200 & 588 & 39.5 \\
\hline \multirow[b]{2}{*}{$n[30]$} & & & - & - & 325 & 325 & 2 & 0.25 & 3.0 & 0.04 & \begin{tabular}{|l|}
0.53 \\
\end{tabular} & 36.4 & 29.2 & 2.24 & 31.6 & 324 & 405 & 200 & 1776 & 52 \\
\hline & A3 & $200 \times 400$ & - & - & 375 & 375 & 2G10-2S10 & 0.25 & 1.5 & 0.03 & 0.2 & 35.3 & 28.2 & 2.20 & 31.2 & 324 & 405 & 200 & 1776 & 52 \\
\hline
\end{tabular}

Notes: The prism compressive strength $R_{b}$, tensile strength $R_{b t}$, and elastic modulus of concrete $E_{b}$ were determined according to the empirical equations as follows: $R_{b}=0.8 R_{m} ; R_{b t}=5 R_{m} /\left(45+R_{m}\right), \mathrm{MPa} ; E_{b}=55000 R_{m} /\left(27+R_{m}\right), \mathrm{MPa}$.

Table 3 The comparison in results between the experiment and theory

\begin{tabular}{|c|c|c|c|c|c|c|c|c|c|c|c|}
\hline \multirow[b]{2}{*}{ References } & \multirow[b]{2}{*}{ Beam ID } & \multicolumn{3}{|c|}{ Experimental } & \multicolumn{6}{|c|}{ Theoretical } & \multirow[b]{2}{*}{$\begin{array}{l}M_{u, t} \\
M_{u, e}\end{array}$} \\
\hline & & $\begin{array}{c}M_{c r c, e}, \\
k N m\end{array}$ & $\begin{array}{l}M_{u, e}, \\
k N m\end{array}$ & Failure mode & $\begin{array}{c}\mu_{s g} \\
(18)\end{array}$ & $\begin{array}{c}\mu_{s g, \min } \\
\text { (20) }\end{array}$ & $\begin{array}{c}\mu_{s g, E} \\
(25)\end{array}$ & $\begin{array}{c}\mu_{s g, \max } \\
(26)\end{array}$ & Case study & $M_{u, t}, k N m$ & \\
\hline \multirow{2}{*}{ This study } & B1 & 5.70 & 5.85 & $\mathrm{SY}, \mathrm{RG}$ & 2.18 & 2.8 & 0.11 & 5.82 & $\mu_{s g}<\mu_{s g, \min }$ & $5.7(11)$ & 0.97 \\
\hline & $\mathrm{B} 2$ & 7.10 & 68.10 & $\mathrm{CC}$ & 109.1 & 3.24 & 4.51 & 4.44 & $\mu_{s g, E>} \mu_{s g, \max }$ & $69.3(28)$ & 1.02 \\
\hline Lau and Pam[29] & G03MD1 & - & 147.7 & $\mathrm{SY}, \mathrm{RG}, \mathrm{CC}$ & 13.6 & 2.03 & - & - & $\mu_{s g}>\mu_{s g, \min }$ & $157.7(13)$ & 1.07 \\
\hline \multirow{2}{*}{ Tan [30] } & $\mathrm{A} 2$ & - & 43.5 & SY, RG, CC & 8.6 & 2.05 & - & - & $\mu_{s g}>$ & $44.2(13)$ & 1.02 \\
\hline & $\mathrm{A} 3$ & - & 35.3 & SY, RG, CC & 4.4 & 1.56 & - & - & $\mu_{s g}>\mu_{s g, \min }$ & $34.2(13)$ & 0.97 \\
\hline
\end{tabular}

Notes: SY - steel yielding, RG - rupture of GFRP, CC - concrete crushing, the number in brackets () shows the sequence number of equations.

All beams were tested up to failure under a monotonic load in the four-point bending test, as shown in Figs. 6 and 7 after 28 days of curing. The maximum midspan deflection of the beam was measured using a linear variable differential transformer. Two indicators, I1 and I2, installed at two supports were used to eliminate the displacements of the supports. Two strain gauges, $\mathrm{S} 1$ and S2, were attached to record the strains in the steel bars and GFRP bars, respectively. The test was performed by means of displacement control at 1.8-2.2 $\mathrm{mm} / \mathrm{min}$, and the loading was paused at intervals of 10-15 $\mathrm{s}$ to record data from the dual indicators. The load value was measured by a load cell. The data from indicators were collected by the naked eye; all other data were automatically recorded by an acquisition system (STS-Wifi, USA). 


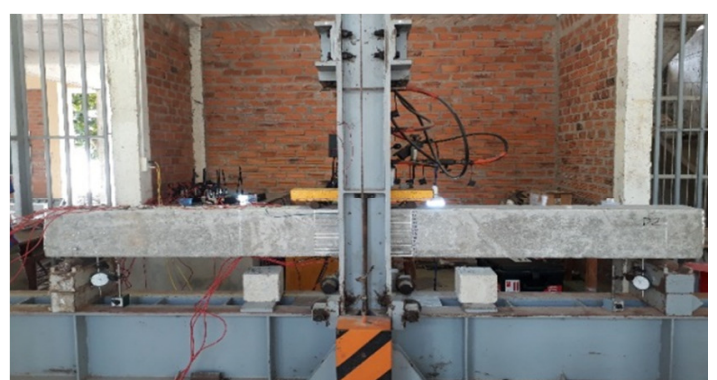

Fig. 7 Bending test for the hybrid GFRP/steel RC beam

Fig. 8 presents the relationship between the load and midspan deflection of the tested beams. The relationship between the moment and strains in materials at midspan is shown in Fig. 9. During the testing of beam B1, the first crack appeared at one of the loading points, and then at other loading points and at midspan. After the crack appeared at midspan, the stiffness of the beam significantly decreased, as shown by the jump in the load-deflection and moment-strain diagrams in Fig. 8(a) and Fig. 9(a), respectively. Consequently, the midspan deflection and strains in the GFRP and steel bars developed rapidly, leading to the yielding of steel and rupturing of the GFRP bar with negligible load gain. After the rupture of the GFRP bar, the concrete in the compression zone was suddenly crushed (Fig. 10(a)) while the steel was still yielding; and the test was stopped immediately to protect the instruments. It can be seen from Fig. 8(a) and Fig. 9(a) that the maximum load on beam B1 at failure is almost equal to the cracking load. Fig. 10(a) shows that there are only two minor cracks at the loading points and one major crack at midspan at the moment of failure.

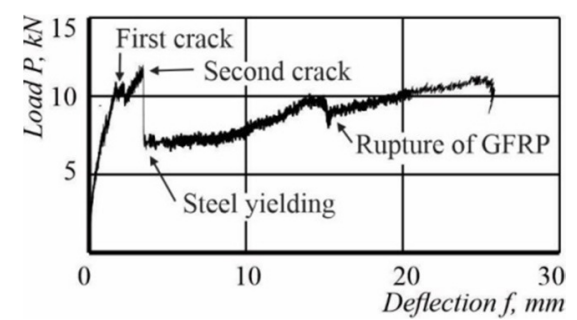

(a) Load versus deflection graph of beam B1

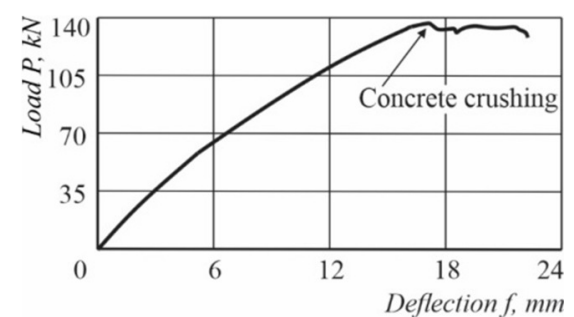

(b) Load versus deflection graph of beam B2

Fig. 8 Relationships between load and midspan deflections of tested beams B1 and B2

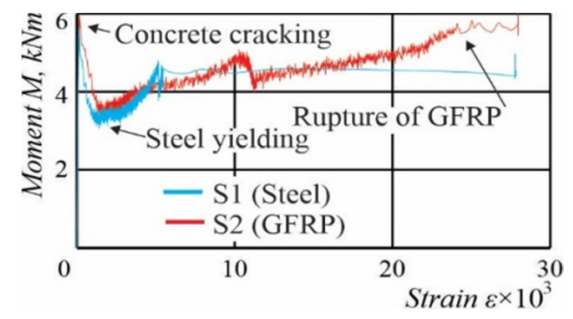

(a) Beam B1

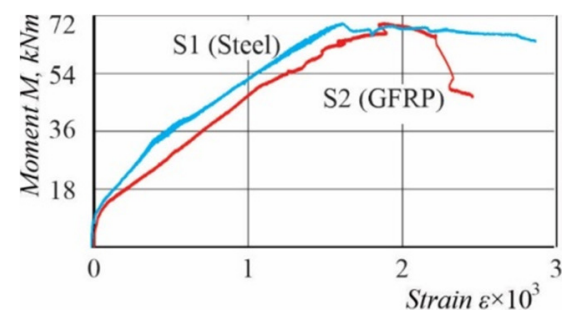

(b) Beam B2

Fig. 9 Relationships between bending moments and strains in steel and GFRP bars of tested beams B1 and B2

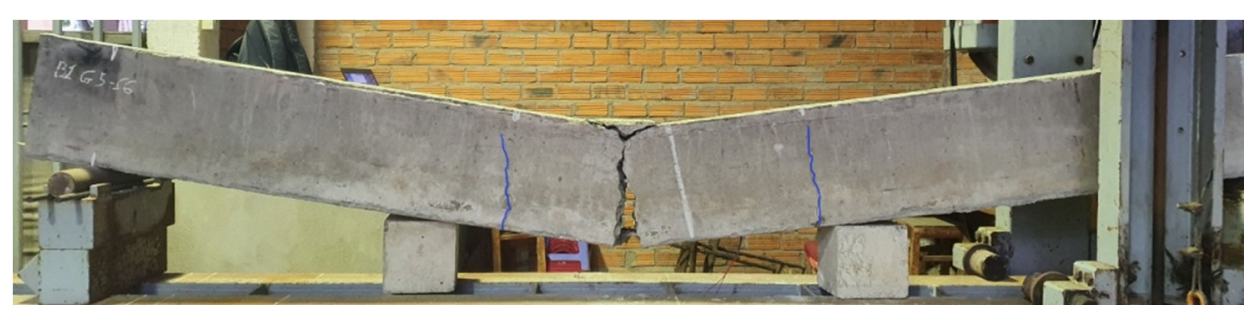

(a) Beam B1

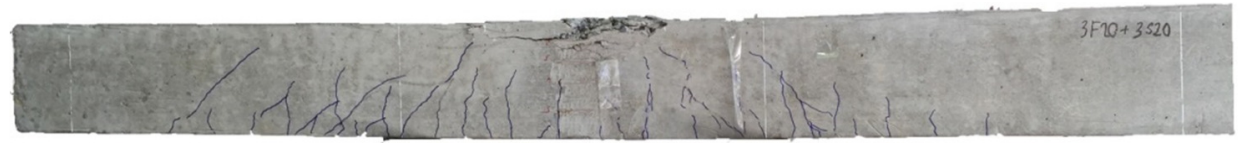

(b) Beam B2

Fig. 10 Crack patterns and failure modes of tested beams 
Owing to the high hybrid reinforcement ratio, after the appearance of the first crack, the deflection and strains in the GFRP and steel bars of beam B2 developed almost linearly until failure, as shown in Fig. 8(b) and Fig. 9(b). Failure of beam B2 occurred by the concrete crushing in the compression zone without the yielding of steel bars and rupturing of GFRP bars (Fig. $10(\mathrm{~b}))$. At the point of maximum load, the strain in steel bar $\varepsilon_{s}$ and GFRP bars $\varepsilon_{g}\left(\varepsilon_{s}=1.6 \times 10^{-3}\right.$ and $\left.\varepsilon_{g}=1.85 \times 10^{-3}\right)$ were lower than the yield strain of steel $\left(\varepsilon_{s y}=\sigma_{s y} / E_{s}=2.05 \times 10^{-3}\right)$ and ultimate strain of GFRP bars $\left(\varepsilon_{g u}=R_{g} / E_{g}=21.9 \times 10^{-3}\right)($ Fig. $9(\mathrm{~b}))$, respectively.

To compare the experimental and theoretical results, the minimum and maximum reinforcement ratios as well as the moment capacity of the tested hybrid GFRP/steel RC beams were calculated using the analytical equations proposed in Sections 2 and 3. The material properties used in the calculations are listed in Table 2. The strength reduction factor of the beam $(\phi)$ used in the calculation is equal to 1 . A comparison of the experimental and theoretical results, presented in Table 3 , showed good agreement.

\section{Conclusions}

In this work, an analytical formula for determining the minimum hybrid GFRP/steel reinforcement for a concrete beam to prevent the GFRP rupture failure upon concrete cracking is proposed by equating the cracking moment of a plain concrete beam and the load-carrying capacity of a hybrid GFRP/steel under RC beam. The formula for limiting the maximum hybrid GFRP/steel reinforcement for concrete beam was also introduced based on the equilibrium of forces in the balanced failure mode of a hybrid GFRP/steel RC beam, in which concrete crushing and yielding of steel occurred simulatensouly. The recommendations for determining the load-carrying capacities of concrete beams with GFRP/steel reinforcement less than the minimum required amount, or more than the maximum amount, are presented. Accordingly, the load-carrying capacity for the first case was assumed to be equal to the cracking moment of the plain concrete beam, whereas the load-carrying capacity for the latest case was determined as balanced failure.

The equations proposed in this study were validated by the results of experiments conducted by the authors and the available experimental results in the literature. A comparison of theoretical and experimental results showed a deviation of less than $7 \%$.

It should be noted that the above conclusions are based on the theoretical approach and limited experimental data. Further research on this topic through experimental, numerical, and parametric studies on various types of FRP reinforcements and concrete will be conducted to verify the accuracy of the proposed theory.

\section{Conflicts of Interest}

The authors declare no conflict of interest.

\section{References}

[1] C. Jeetendra, K. Suresh, and A. Hussain, “Application of FRP in Concrete Structures,” International Journal of Engineering Associates, vol. 4, pp. 50-51, January 2015.

[2] S. B. Singh, Analysis and Design of FRP Reinforced Concrete Structures, New Delhi: McGraw-Hill Education, 2015.

[3] L. Ade and P. Purwanelson, "Axial and Flexural Strength of Square RC Columns with No-rounded Corners Wrapped with CFRP under Eccentric Loading,” International Journal of Engineering and Technology Innovation, vol. 8, no. 1, pp. 38, January 2018.

[4] A. E. Uğur, A. Ünal, B. A. Akgöbek, M. Kamanlı, and S. Cengiz, "Use of GFRP Bar in Civil Engineering,” 4th International Symposium on Innovative Approaches in Engineering and Natural Sciences (ISAS WINTER-2019), July 2019, pp. 95-100. 
[5] B. Benmokrane and R. Masmoudi, "Flexural Response of Concrete Beams Reinforced with FRP Reinforcing Bars," Structural Journal, vol. 93, no. 1, pp. 46-55, January 1996.

[6] M. Konsta-Gdoutos and C. Karayannis, "Flexural Behaviour of Concrete Beams Reinforced with FRP Bars," Advanced Composites Letters, vol. 7, no. 5, pp. 133-138, January 1998.

[7] C. Barris, L. Torres, J. Comas, and C. Miàs, "Cracking and Deflections in GFRP RC Beams: An Experimental Study," Composites Part B: Engineering, vol. 55, pp. 580-590, December 2013.

[8] A. Ramachandra Murthy, D. M. Pukazhendhi, S. Vishnuvardhan, M. Saravanan, and P. Gandhi, "Performance of Concrete Beams Reinforced with GFRP Bars under Monotonic Loading," Structures, vol. 27, pp. 1274-1288, October 2020.

[9] M. Aiello and L. Ombres, "Structural Performances of Concrete Beams with Hybrid (Fiber-Reinforced Polymer-Steel) Reinforcements," Journal of Composites for Construction, vol. 6, no. 2, pp. 133-140, January 2002.

[10] H. Y. Leung and R. V. Balendran, "Flexural Behaviour of Concrete Beams Internally Reinforced with GFRP Rods and Steel Rebars," Structural Survey, vol. 21, no. 4, pp. 146-157, October 2003.

[11] W. Qu, X. Zhang, and H. Huang, "Flexural Behavior of Concrete Beams Reinforced with Hybrid (GFRP and Steel) Bars," Journal of Composites for Construction, vol. 13, no. 5, pp. 350-359, March 2009.

[12] X. Ruan, C. Lu, K. Xu, G. Xuan, and M. Ni, "Flexural Behavior and Serviceability of Concrete Beams Hybrid-Reinforced with GFRP Bars and Steel Bars," Composite Structures, vol. 235, p. 111772, March 2020.

[13] Y. Yang, Z. Y. Sun, G. Wu, D. F. Cao, and Z. Q. Zhang, "Flexural Capacity and Design of Hybrid FRP-Steel-Reinforced Concrete Beams," Advances in Structural Engineering, vol. 23, no. 7, pp. 1290-1304, December 2019.

[14] X. Gu, Y. Dai, and J. Jiang, "Flexural Behavior Investigation of Steel-GFRP Hybrid-Reinforced Concrete Beams Based on Experimental and Numerical Methods," Engineering Structures, vol. 206, p. 110117, March 2020.

[15] P. D. Nguyen, V. H. Dang, and N. A. Vu, "Performance of Concrete Beams Reinforced with Various Ratios of Hybrid GFRP/Steel Bars,” Civil Engineering Journal, vol. 6, no. 9, pp. 1652-1669, September 2020.

[16] L. Pang, W. Qu, P. Zhu, and J. Xu, "Design Propositions for Hybrid FRP-Steel Reinforced Concrete Beams," Journal of Composites for Construction, vol. 20, no. 4, p. 04015086, December 2015.

[17] J. Zhang, W. Ge, H. Dai, and Y. Tu, "Study on the Flexural Capacity of Concrete Beam Hybrid Reinforced with FRP Bars and Steel Bars," 5th International Conference on FRP Composites in Civil Engineering (CICE 2010), September 2010, pp. 304-307.

[18] B. Jia, S. Liu, X. Liu, and R. Wang, "Flexural Capacity Calculation of Hybrid Bar Reinforced Concrete Beams," Materials Research Innovations, vol. 18, no. sup2, pp. S2-836-S2-840, May 2014.

[19] SP 63.13330, Concrete and Reinforced Concrete Structures, General provisions, 2018.

[20] ACI 318, Building Code Requirements for Structural Concrete, American Concrete Institute, 2019.

[21] M. N. Hassoun and A. Al-Manaseer, Structural Concrete: Theory and Design, 7th ed. Wiley, 2020.

[22] SP 295.1325800, Concrete Structures Reinforced with Fibre-Reinforced Polymer Bars, Design Rules, 2017.

[23] ACI 440.1R, Guide for the Design and Construction of Structural Concrete Reinforced with FRP Bars, 2015.

[24] A. Carpinteri, Applications of Fracture Mechanics to Reinforced Concrete, 1st ed. New York: CRC Press, 1992.

[25] T. M. Fayyad and J. Lees, "Evaluation of a Minimum Flexural Reinforcement Ratio Using Fracture-Based Modelling," IABSE Symposium Report, vol. 105, no. 35, pp. 1-8, September 2015.

[26] A. Nanni, A. De Luca, and H. J. Zadeh, Reinforced Concrete with FRP Bars: Mechanics and Design, CRC Press, 2014.

[27] Q. S. Khan, S. M. Neaz, and M. N. S. Hadi, “Tension and Compression Testing of Fibre Reinforced Polymer (FRP) Bars," The 12th International Symposium on Fiber Reinforced Polymers for Reinforced Concrete Structures (FRPRCS-12) \& The 5th Asia-Pacific Conference on Fiber Reinforced Polymers in Structures (APFIS-2015), December 2015, pp. 1-6.

[28] J. Ožbolt and M. Bruckner, "Minimum Reinforcement Requirement for RC Beams," European Structural Integrity Society, vol. 24, pp. 181-201, 1999.

[29] D. Lau and H. Pam, "Experimental Study of Hybrid FRP Reinforced Concrete Beams," Engineering Structures, vol. 32 , no. 12, pp. 3857-3865, December 2010.

[30] K. H. Tan, "Behavior of Hybrid FRP-Steel Reinforced Concrete Beams," Third International Symposium on Non-Metallic (FRP) Reinforcement for Concrete Structures (FRPRCS-3), October 1997, pp. 487-494.

Copyright $(\mathrm{C}$ by the authors. Licensee TAETI, Taiwan. This article is an open access article distributed under the terms and conditions of the Creative Commons Attribution (CC BY-NC) license (https://creativecommons.org/licenses/by-nc/4.0/). 